\title{
AMBRA1 links autophagy to cell proliferation and tumorigenesis by promoting c-Myc dephosphorylation and degradation
}

Valentina Cianfanelli, Claudia Fuoco, Mar Lorente, Maria Salazar, Fabio Quondamatteo, Pier Federico Gherardini, Daniela De Zio, Francesca Nazio, Manuela Antonioli, Melania D’Orazio, Tatjana Skobo, Matteo Bordi, Mikkel Rohde, Luisa Dalla Valle, Manuela Helmer-Citterich, Christine Gretzmeier, Joern Dengjel, Gian Maria Fimia, Mauro Piacentini, Sabrina Di Bartolomeo, Guillermo Velasco and Francesco Cecconi

Nat. Cell Biol. 17, 20-30 (2015); published online 1 December 2014; corrected after print 1 April 2015

In the version of this Article originally published, incorrect western blot scans were provided for the actin panels in Figure $4 \mathrm{~h}$,i. These panels have been corrected online and are shown below. All samples in $4 \mathrm{i}$ were collected and processed simultaneously, on the same or on parallel gels/blots.

h $M_{\mathrm{r}}(\mathrm{K})$

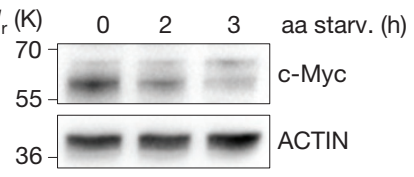

i $\underline{\text { CTRL siRNA }} \frac{\text { AMBRA1 siRNA }}{\text { SiRNA no. } 1 \text { siRNA no. } 2}$

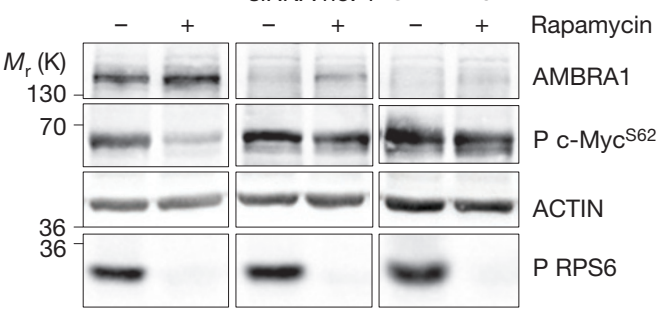

